\title{
AC 2008-2811: EMBEDDED DESIGN IN A SOPHOMORE COURSE
}

Daren Wilcox, Southern Polytechnic State University

1100 South Marietta Parkway Marietta, Georgia 30060-2896, USA +1 678-915-7269 dwilcox@spsu.edu

\section{Steve Wilson, Southern Polytechnic State University}

1100 South Marietta Parkway Marietta, Georgia 30060-2896, USA +1 678-915-7246 swilson3@spsu.edu

\section{Gerd Wostenkuhler, Hochschule Harz}

(University of Applied Studies and Research) Friedrichstraße 57-59 D-38855 Wernigerode, Germany+493943659-322 gwoestenkuehler@hs-harz.de 


\title{
Embedded Design in a Sophomore Course
}

\begin{abstract}
Recently in academia, a push has emerged to include engineering design early in a student's course sequence. The desired result is to captivate the student's interest in engineering before the student has had a chance to change majors. Otherwise, the student would not experience the design process until the capstone courses in the senior year. In this paper, an embedded design project in a sophomore course is presented. The design project is based on the USB Toolstick from Silicon Laboratories. The USB Toolstick is an 8051 series microcontroller that is self contained, economical, and very student friendly. What follows is a discussion of the sophomore course, an overview of the USB Toolstick, and examples of embedded design based on the Toolstick.
\end{abstract}

\section{Introduction}

The sophomore course referred to in this paper is the second course of the digital design sequence in the electrical engineering technology program at Southern Polytechnic State University. Southern Polytechnic State University was founded in 1948 as a unit of the Georgia Institute of Technology at the request of the Georgia Business and Industry Association ${ }^{1}$. In 1949 it was named Southern Technical Institute. In 1970, it separated from Georgia Tech while becoming one of the first colleges to offer the bachelor of engineering technology degree. In 1987 it became the Southern College of Technology. In 1996 it reached university status. Throughout its history, Southern Poly has responded to the applied engineering and technology requirements of the state and region. Having graduates that not only can design, but see the design to implementation has been the core pedagogy of the institute since its inception. In virtually every course, an element of design is required of the student. In the second course of the digital design sequence, students are required to complete three design projects.

The sophomore in the second digital design course is taught digital design through three projects. The first project currently uses discrete digital ICs and simple programmable logic devices (SPLD). The project is usually designing a state machine system such as a traffic light with additional features. Perhaps the traffic light has turn lanes that monitor the number of vehicles waiting to turn. Or perhaps the traffic light is situated near a railroad crossing. Or perhaps the traffic light is located on a secured installation such as an air base that might need to deploy security measures such as tire spikes. The design is limited to discrete components and SPLDs thereby forcing the student to learn components of design that cannot be taught in class. Critical to the design process is learning how to interface the devices. All electrical specifications must be taken into consideration in interconnecting the discrete devices. Then, if the design does not meet requirements or malfunctions, the student learns to trouble shoot and verify logic. The entire process requires more than a couple of weeks so students learn project management skills. After the completion date, the students learn documentation skills and the value of having started the documentation early in the design. The first project is weighted so that hardware design and implementation is worth just as much as the resulting documentation. In this way, failure to meet all design objectives does not result in project failure. Quite often, it is that the failures are more important than the successes.

The second project is usually an extension of the first design but using more advanced digital devices such as complex programmable logic devices (CPLD). The advanced devices allows for more digital 
logic to be implemented on a single IC. As a direct result, fewer lessons are learned in interfacing and trouble shooting. However, more VHLD software design and software project management is learned. The project lasts more than a couple of weeks. The student success rate increases and the documentation improves.

The third project is where the student is expected to apply the lessons learned in designing such as project management, interfacing and trouble shooting, toward a small embedded system. The embedded design centers on a microcontroller of the Intel 8051 family, the Silicon Laboratories C8051F330-GP. In addition, the design must consist of a combination of sensor, actuator, analog-to-digital converter, digital-to-analog converter, and some small system to control. The proposal and review process goes through a couple of iterations until a project is agreed upon, or coerced. It is then the responsibility of the student to acquire needed materials, construct the prototype, and present the results in class presentations. The students have about four weeks to complete the design. For most students, this project ends the semester.

\section{Overview of Silicon Labs USB ToolStick}

Of the 8051 family of microcontrollers used in the third project to date, the Silicon Laboratories C8051F330 has been the most student friendly and economical. The C8051F330 is emulated using what Silicon Labs refers to as the USB ToolStick which is shown in Figure 1. The ToolStick has a main module, the base adapter, which handles communication to the host computer through the USB port. It is also powered by the USB port. The C8051F330 microcontroller is emulated on a daughter card that connects to the main module ${ }^{2}$. The daughter card has soldering pads available for all port pins of the microcontroller as shown in Figure 2. The students can purchase the USB ToolStick for around \$25. The software for compiling the assembly or $\mathrm{C}$ code and subsequent emulation is available for free download on the Silicon Labs website, www.silabs.com/toolstick. The software is termed the Integrated Development Environment (IDE). As a package, the USB ToolStick replaces development systems that have cost several hundred dollars.

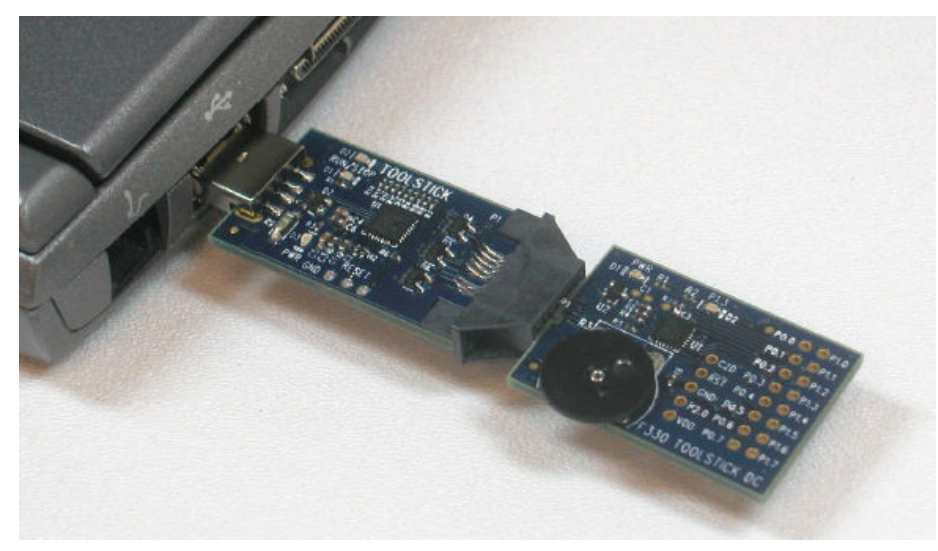

Figure 1: Silicon Laboratories USB ToolStick ${ }^{2}$ (courtesy of Silicon Labs.) 


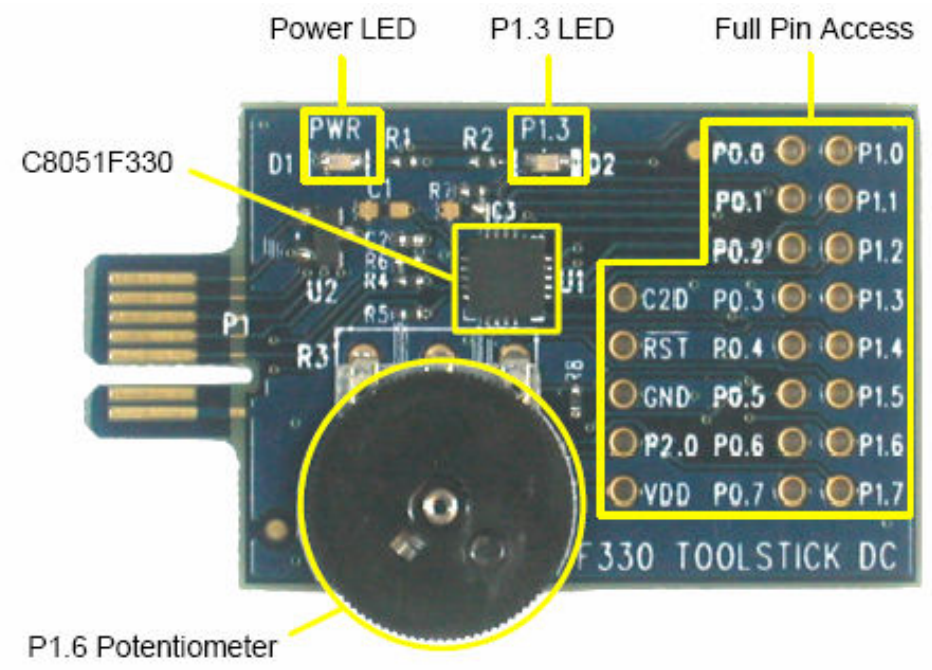

Figure 2: Silicon Laboratories C8051F330 Daughter Card ${ }^{2}$

(courtesy of Silicon Labs.)

The C8051F330 microcontroller is emulated using the C8051F330 Daughter Card shown in Figure 2. The microcontroller is the $3 \mathrm{~mm} \times 3 \mathrm{~mm}$ IC located at the center of the board. Each of the pins is accessible in the solder pad area shown on the right. In addition, port pin P1.6 is connected to a thumb wheel potentiometer. The potentiometer provides an adjustable analog voltage input for code development or demonstration. Port pin P1.3 is connected to an LED. The LED provides a simple output for code development or demonstration. Should full in-circuit emulation be desired, a 20 pin male connector can be soldered to the pad. The pins can then be brought out to a circuit board through a flat ribbon cable and a 20 pin male header. However, the daughter card will need to be modified by removing the R2 resistor from P1.3 and the R8 resistor from P1.6. Additional consideration is required for the pins /RST and P2.0 which are used for communication with the base adapter. Application Note AN124 addresses concerns with these pins. From a student standpoint, most designs can be implemented using the two eight bit ports P0 and P1 and VDD and GND.

An equivalent 20 pin dual-in-line package (DIP) of the C8051F330 is available. The part number is C8051F330-GP and sells for around \$5. The student can use the USB ToolStick with the C8051F330 Daughter Card and emulate the assembly or $\mathrm{C}$ code in the IDE software. After the software bugs are worked out, the student can download the Intel HEX code to the C8051F330-GP using a standard universal EEPROM programmer such as the GALEP4 from Connitec. It is also possible to program the C8051F330-GP DIP microcontroller using another daughter card available from Silicon Labs.

The ToolStick Debug Adapter Daughter Card is shown in Figure 3 connected to the base adapter. The flat ribbon cable brings out the JTAG and C2 debug interfaces to the target device's in-system debug/programming circuitry. The debug adapter can also provide USB power to the target system up to $75 \mathrm{~mA}$ at $5 \mathrm{~V}^{3}$ 


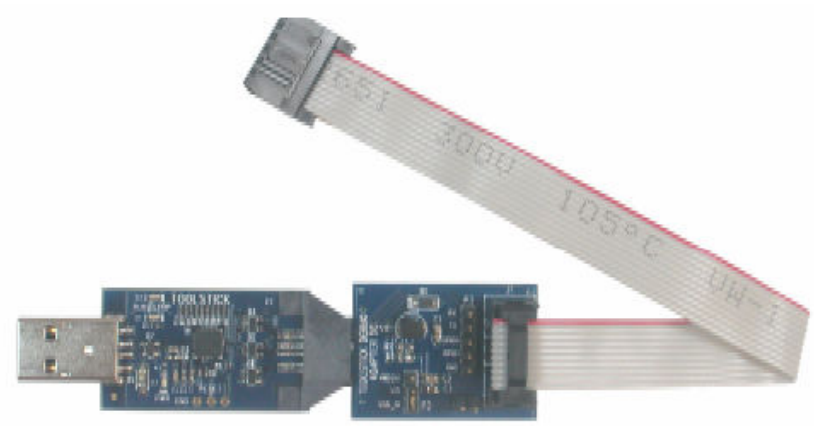

Figure 3: Silicon Laboratories Debug Adapter Daughter Card ${ }^{3}$ (courtesy of Silicon Labs.)

The student can use the debug adapter to program a 20 pin DIP version of the C8051F330 by connecting the ribbon cable as shown in Figure 4. The student can place the microcontroller onto a breadboard and connect the pins as shown. Then within the IDE software environment, the student can download the compiled assembly or $\mathrm{C}$ code directly to the microcontroller. The debug adapter costs around $\$ 9$.

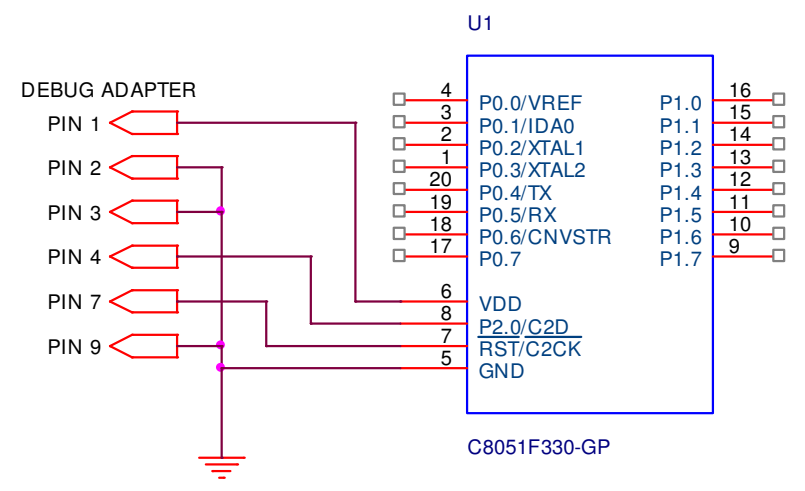

Figure 4: Programming the C8051F330-GP DIP Using the Debug Adapter

\subsection{Configuring the ToolStick Debug Adapter for Programming}

1. Place the jumper $\mathrm{J} 1$ in the appropriate position for the $\mathrm{I} / \mathrm{O}$ voltage of the Target Board being used. Connect pins 1 and 2 (VREG and VIO) for $2.5 \mathrm{~V} \mathrm{I/O}$ or connect pins 2 and 3 (VDD and VIO) for $3.3 \mathrm{~V}$ I/O.

2. If the Target Board will be powered from the ToolStick Debug Adapter, place a jumper on header J2. If the Target Board will be separately powered, ensure that no jumper is installed on header J2.

Note: Powering the Target Board from the ToolStick Debug Adapter and a separate power supply at the same time could cause damage to the ToolStick Base Adapter and/or the Target Board ${ }^{3}$. 


\section{Embedded Design Examples}

Presented are two embedded designs which reflect common student projects. The first is an "automated beverage server". In this project, two sophomore students modified a toy remote controlled car to serve beverages about a room. The beverage server is shown in Figure 5. The remote controlled car platform served as the system to be controlled. Toys are very inexpensive platforms to build embedded control systems around. All of the mechanical aspects are already in place. Some of the electronics such as power transistors are also available. The student can reverse engineer the digital control lines to the $\mathrm{H}$ bridge transistor arrays. By monitoring the voltage levels on the lines as the vehicle is signaled to go forward, reverse, left, and right, the students can create a table of required logic signals on those lines. The student can then cut the trace and solder to those points their own control lines. The C8051F330GP along with other logic can serve as the new controller to the toy car.

In this type of project, the student learns how to electrically interface digital circuits to power electronic circuits. In addition, the student must become creative in mechanically fastening the circuit board to the toy car. The student also demonstrates an understanding of programming the microcontroller. Since every dorm room needs an automated beverage server, the students find the project enjoyable and rewarding.

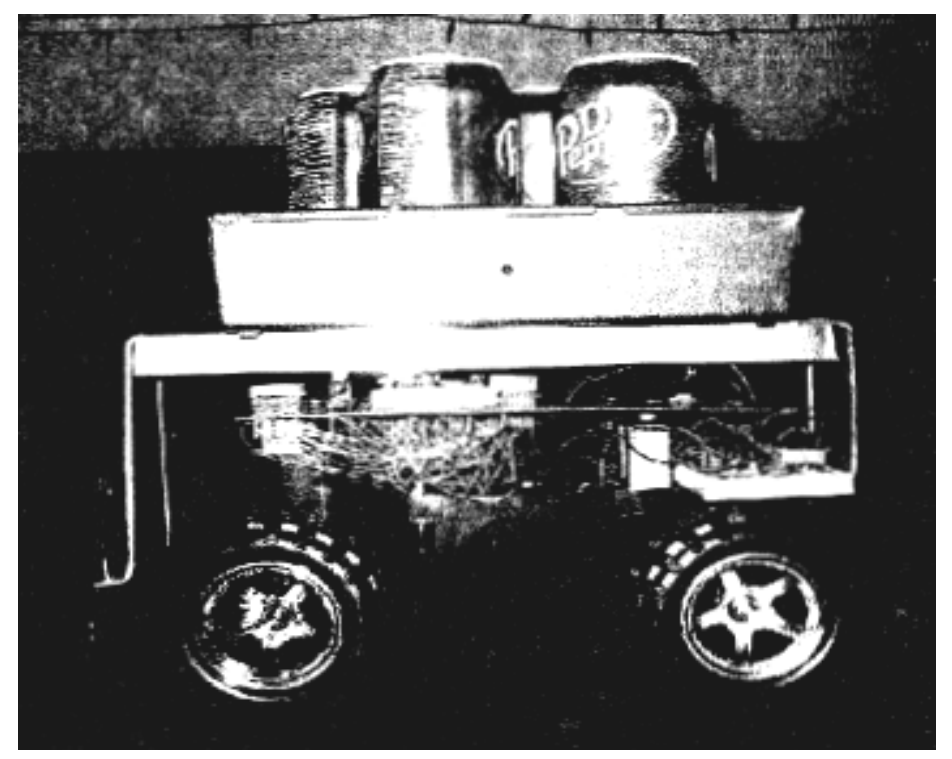

Figure 5: Automated Beverage Server

The second project is a "mini basket ball game controller". In this project, students obtained a toy basketball game and removed all electronics. Then the students attached phototransistor sensor to the basketball rim. The circuit board contained seven segment displays driven by an ispM4A5 CPLD. The CPLD displayed the timer counting down along with the current score. The microcontroller kept time along with the score. A push button started the process. The game is shown in Figure 6. 


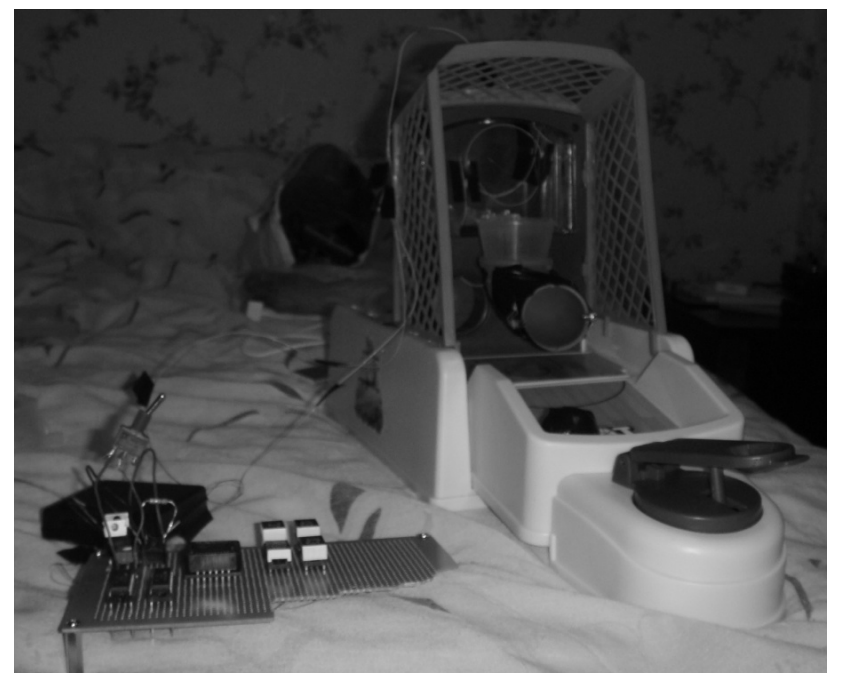

Figure 6: Mini Basketball Game Controller

\section{Conclusion}

The embedded design process can be easily taught at the sophomore level. The key to teaching design is to step the students through the design process in varying degrees. By having three projects in a semester of increasing complexity, the students are given plenty of chances to learn through mistakes. The students must learn project management skills, interfacing skills, documentation skills, and the actual lecture material of the textbook. By the third project, the students know what to expect and are more independent when designing. The USB ToolStick Starter Kit from Silicon Laboratories offers an excellent design platform to accomplish the embedded design. The kit is economical and very student friendly.

\section{Acknowledgements}

The authors would like to thank Dan Pratt of Lattice Semiconductors for generous support of laboratory equipment and software for Southern Polytechnic and Hochschule Harz. Furthermore, the authors would like to thank students Scot Poore, James Julien, Jason Seide, and Phoenexay Keodouangdy for their hard work and contributions to this paper.

\section{References}

1. Southern Polytechnic State University, http://www.spsu.edu/home/about/history.html, (17 Jan. 2008)

2. Silicon Laboratories, ToolStick C8051F330 Daughter Card User's Guide, Rev. 0.3 1/07

3. Silicon Laboratories, ToolStick Debug Adapter User's Guide, Rev. 0.1 9/06 